\title{
The Effect of Weekly Quizzes on Students' Final Achievement Score
}

\author{
Valeh Gholami \\ University of Tabriz, Iran \\ vale.gholami@yahoo.com \\ Mostafa Morady Moghaddam \\ Young Researchers Club, Mashhad Branch, Islamic Azad University, Mashhad, Iran \\ mostafa_morady@yahoo.com
}

\begin{abstract}
The present study aimed at investigating the effect of weekly quizzes on Iranian high school students' performance on final achievement tests. This effect, which is technically referred to as washback, is defined as the effect of testing on learning and teaching. Most scholars have attempted to provide guidelines in order to achieve positive washback. While some suggest frequent quizzes as a means of positive washback, others oppose the idea. The proponents claim that frequent quizzes stimulate practice and review, give the students more opportunities for feedback and have a positive influence on students' study time. The opponents, on the other hand, believe that too frequent testing might inhibit of larger units of instructional material and frustrate anxious students, and thus, hinder learning. This study explored whether students taking weekly quizzes performed better in the final achievement tests. 70 students studying in grade two of high school were selected and divided into two groups. One group received weekly quizzes and the other group took only midterm exam. The results indicated that the group with weekly quizzes performed better than the group without quizzes.
\end{abstract}

Index Terms - Quiz, Washback, Students' performance, Formative assessment, Achievement test

\section{INTRODUCTION}

Interest in how to improve students learning is not new. It is generally assumed that quizzes are useful tools to enhance learning and consolidate what has been taught. Brown (2004) conceives of them as "the information that washes back to students in the form of useful diagnoses of strengths and weaknesses" (p. 29). This influence of the test on the classroom can be either beneficial or harmful.

In one of the few published studies of frequent quizzing, Geist and Soehren (1997) reported on a study of dental students. They concluded that frequent quizzing had a beneficial and significant influence on student performance. They further found that the positive effects on performance increased as the number of quizzes increased. Thus they concluded that quizzes do matter for academic performance and teaching had an influential autonomous effect on learning.

Quizzes can be beneficial in a number of ways. First, they supply motivation for students to attend classes (Zarei, 2008). In a study, wilder (2001) examined the effect of random quizzes on student attendance in an undergraduate course on the psychology of learning. The results indicated that student attendance increased by 10 percent when the quizzes were in place.

Frequent quizzes help students to retain the material for longer period of time or make them ready for highstakes exams (Johnsom \& Kiviniemi, 2009). In addition, many studies have shown that frequent testing increases student's classroom attendance (Chump, Bauer, \& Alex, 2003; Jones, 1984; Wilder, Flood, \& Stromsnes, 2001).

The difference between instructed and naturalistic learning should be taken into consideration too. As it is mentioned by Pica (1983), in every second language context a distinction is to be made between instructed and naturalistic learning. Instructed learning can be defined in various forms based on setting, motive, and process (Ellis, 2005). In terms of motive and process, the distinction is not clear-cut. But for the setting, instructed learning takes place in classrooms and naturalistic learning takes place in real environment where the language is used to communicate and not just for metalinguistic analysis. Task-Based instruction was an attempt to provide learners with naturalistic way of learning in which communicating and achieving one's goals through manipulating the language took outmost importance. White (1988), distinguished between two types of curriculum: Type A Curriculum and Type B Curriculum. In the former, there is a graded list of items that should be learned one by one in a structural syllabus but in the later learners are provided with tasks to use their language experientially. The tasks have a strong motivational power since they make the language learning process meaningful. Hence, the skills are integrated in order to accomplish a task. Therefore, as Widdowson (1988) mentioned it, the skill getting process turns to a skill using one.

Ellis (2005, pp. 720-721) pinpointed the underlying elements of task-base instruction approach as: 
- Meaning is primary

- There is some communication problem to solve

- There is some relationship to real-world activities

- Task completion has some priority

- Assessment of the task is in terms of outcome

Prabhu (1987) was one of the pioneers who advocated the use of tasks as a substitute to preselectoin of linguistic elements and mentioned that learning process should take place in a holistic way. The main implication of his study was to deemphasize the metalinguistic approach toward learning a language in which the main focus is on talking about the language instead of using the language in communicative activities. Prabhu proposed a procedural syllabus paved the way to develop a syllabus based on using task as a motive to change the traditional stereotype of learning a language - which was a structural syllabus. The motto changed to this one: communicate in order to learnwhich was traditionally: first learn then communicate. The Prabhu model of task-based instruction was a radical one. He believed that in order for successful language learning to take place one should learn the language implicitly without conscious attention to form. Another seminal work which paved the way for many studies in task-based approach is related to Long (1985). Both Prabhu and Long were interested in task-based teaching; however, their approach was different. For Prabhu, the main concern was learning a language implicitly but Long emphasized on a theory of language which is integrated with some sort of attention to from or what he calls 'focus on form'. Long further distinguished between two types of tasks: target and pedagogic. As Long put it, need analysis is the starting point in every task-based syllabus.

Therefore, the investigators hypothesized that students with weekly quizzes not only perform better on tests but also learn more. This study attempted to answer that whether administering weekly quizzes results in better performance on final achievement tests.

\section{REVIEW OF THE RELATED LITERATURE}

The term frequent testing has been subject to many different interpretations and definitions. Some define frequent testing as a kind of examination which is carried out weekly (Keys, 1934), others as a kind of assessment which is performed on a daily basis (Dineen, Taylor, \& Stephens, 1989), while other researchers define it on a monthly basis (Kling, Miller, \& Reardon, 2005).

The relevant literature on frequent quizzing has witnessed a substantial amount of controversy. On the one hand, the proponents of quizzes believe that quizzes have undeniable advantages; frequent quizzes help students to retain the material for longer periods of time or make them ready for high-stakes exams (Johnson \& Kiviniemi, 2009). Taking into consideration the kinds of nation-wide and high-stakes tests, students are required to take frequent testing in order to be prepared for much important exams (Johnson \& Kiviniemi, 2009). In addition, many studies have shown that frequent testing increases students' classroom attendance (Clump, Bauer, \& Alex, 2003; Jones, 1984; Wilder et al., 2001). Frequent testing is also beneficial because through giving students frequent quizzes, schools can gain valuable information about how they are doing. Moreover, frequent testing can provide the school, teachers, parents, and students with useful feedback on student performance in the class (Bangert-Drowns et al., 1986; Standlee \& Popham, 1960).

One of the other important advantages of frequent testing is that it creates extrinsic motivation for the students; since students want to obtain good grades in the course, they try hard and spend a lot of time preparing for the quizzes (Dustin, 1971). There is another view that getting good grades on quizzes motivates students. This has a circular effect in that students prepare more for the quizzes since the test itself is a good source of motivation (Zarei, 2008).

Another reason why frequent testing is beneficial to students' learning is that frequent testing covers small amounts of materials. Therefore, they are processed more deeply and meticulously (Standlee \& Popham, 1960). Moreover, Selakovich (1962) believes that frequent testing even results in more classroom discussion of the content or material covered in the same class.

As far as stress and anxiety are concerned, Dustin (1971) believes that stress is reduced through frequent testing. Teachers can also make sure that students are doing the required readings and assignments in the class through frequent testing (Connor-Greene, 2000; Weinstein \& Wu, 2009).

On the other hand, there are also a number of issues raised against frequent testing. Administering and scoring tests are really time-consuming and it may take the class time away from efficient instruction. Frequent testing might also become tedious for students and decrease students' interest in the materials and learning in general. Marshall (2007) thinks that too much testing does not lead to fruitful and lifelong learning because teachers put their focus only on the tests and teach to the test, providing their students only with the amount of information they need to do well on the tests. Because teachers teach to the test and students read to the test, learning does not last for a long time.

Many studies have been done regarding the effect of frequent testing on the students' learning and achievement. The earliest study, to the researchers' best knowledge, was conducted by Turney (1931) in an educational psychology course. The participants of the study were classified into two groups based on their performance on the pretest. The experimental group received weekly quizzes and the control group received just one mid-term. It was found that frequency of testing was a source of motivation and resulted in higher performance. 
The next study in chronological order was done by Keys (1934). The students in Keys' research were divided into two groups in which the frequency of testing differed in a way that the experimental group was tested on a weekly basis, while the control group was given tests once a month. The instructor, the content of the course, and the assignments were the same. The experimental group outperformed the control group, suggesting that frequent testing leads to efficient learning.

Martin and Srikameswaran (1974) investigated the effects of frequent testing upon long-term retention of content in a Chemistry class. The study included two groups, experimental and control, and all things including the materials, assignments, teaching methodology, and final exams were exactly the same. The only difference between the groups came with the experimental group taking tests every week. The students in the experimental group outperformed the ones in the control group since they were motivated to do some extra work due to frequent quizzes.

In another study, Fulkerson and Martin (1981) found that frequent testing through short, objective tests resulted in better performance than the longer ones given less frequently to the students. The experimental group in this study was given eight tests; each consisting of 25 questions, while the students in the comparison group received four tests each consisting of 50 questions. Everything in the classroom including the materials and assignments were identical in both groups. The findings were in line with those of Keys (1934) and Dustin (1971). Another study was carried out by Dineen, Taylor, and Stephens (1989) to see the effect of daily frequent testing versus weekly testing on students' performance. The study was carried out in an academic setting where the participants ranged from freshmen to senior students. Although the results of the study revealed that there was no significant difference between the two groups as far as the two methods of evaluation were concerned, the study found that "frequent testing was more effective for the weaker students than the stronger students" (Dineen et al., 1989, p. 200).

All the studies reviewed so far have been carried out on a relatively small scale including no more than a few hundred students. There was a very large scale study done by Khalaf and Hanna (1992), in which nearly 2000 biology students participated. The participants were divided into two groups, experimental and control. The students in the experimental group were given tests every two weeks, while the members of the control group received a test on a monthly basis. Two tests were developed by the researchers to examine the effect of frequent testing on student learning and retention. The first test was given exactly at the end of the semester, and the second one was given three months later. The results of the analysis revealed that frequent testing had a beneficial effect on students' achievement and retention of information.
Geist and Soehren (1997) carried out a study with dental students dividing them into two groups of weekly and no quiz. They found that frequent quizzing had a positive effect on students' performance in a way that students' achievement got better when the frequency of the tests increased.

As to the effect of frequent testing on students' retention of information, a study was conducted by Roediger and Karpicke (2006). The participants of the study consisted of undergraduate university students. The results of the study showed that those students who were tested frequently during the course remembered information better than those who were not given tests frequently.

Another study was conducted in a context similar to that of this study in Iran by Zarei (2008). This study intended to examine the effect of frequent testing on Iranian English students' performance and classroom attendance. The results revealed that the more frequently students were exposed to quizzes, the better their performance appeared to be. Moreover, the results showed that the administration of frequent quizzes had a positive correlation with classroom attendance.

Marcell (2008) carried out a study on online frequent testing. In his study, he compared a group of learners who took quizzes online on the basis of daily readings with the one who was not given any quizzes, whether traditional or online. The results of the study revealed that students tested online came to the class with more preparation and raised more questions and made more comments in the class.

A meta-analysis was conducted by Basol and Johanson (2009) on the effect of different testing frequencies on student learning and exam performance. To this end, the authors made use of 78 studies. The studies were classified into three frequency types: high, medium, and low frequency. The findings of the metaanalysis revealed that although there were no statistically significant differences among the three groups, frequent testing was beneficial to student learning and academic achievement.

\section{METHOD}

\section{A. Participants}

Participants of this experimental study were 70 students which were distributed to different classes. The researchers were the instructors of the classes. Participants were divided into two groups, one serving as experimental group that received weekly quizzes and the other as control group that did not receive weekly quizzes. Since it was not possible to randomly assign subjects to groups, intact classes were used but a semirandom procedure was used to determine which group will be the control and which will be the experimental. 


\section{B. Instruments}

The instruments used in this study included 10 teacher-made tests and a final achievement test containing, spelling, vocabulary, grammar, and reading comprehension subparts.

\section{Procedure}

The experimental group took weekly quizzes for the whole semester and the control group did not take any tests during the course except mid-term exams. The study employed an experimental design. To investigate the effect of quizzes on the final performance, a t-test was used.

\section{RESULTS}

The research question sought to investigate the effect of weekly quizzes on students' final achievement. T-test procedure was used to investigate the results of students' performance on achievement tests. Descriptive and test statistics are summarized in Table I.

\section{TABLE I.DESCRIPTIVE STATISTICS FOR THE T-TEST}

\begin{tabular}{|l|l|l|l|l|}
\hline Group & $\mathrm{N}$ & Mean & $\begin{array}{l}\text { Std. } \\
\text { Deviation }\end{array}$ & $\begin{array}{l}\text { Std. Error } \\
\text { Mean }\end{array}$ \\
\hline quiz & 35 & 18.3857 & 1.48565 & .25112 \\
\hline no quiz & 35 & 17.3429 & 1.41822 & .23972 \\
\hline
\end{tabular}

As it can be seen in Table I, the statistical analysis resulted in a t-value of 3.004 which was significant at .05. This means that quiz group students performed better than no quiz group students. Also, $F$ value which is shown in Table II is more than .05, indicating that two groups were homogeneous.

TABLE II.T-TEST RESULTS

\begin{tabular}{|c|c|c|c|c|c|c|}
\hline & \multicolumn{2}{|c|}{$\begin{array}{c}\text { Levene's Test for Equality } \\
\text { of Variances }\end{array}$} & \multicolumn{4}{|c|}{ T-Test for Equality of Means } \\
\cline { 1 - 7 } & \multirow{2}{*}{$\mathrm{F}$} & $\mathrm{Sig}$ & $\mathrm{t}$ & $\mathrm{df}$ & $\mathrm{Sig}$ (2-tailed) & $\begin{array}{c}\text { Mean } \\
\text { Difference }\end{array}$ \\
\hline Equal variances assumed & .001 & .982 & 3.004 & 68 & .004 & 1.04286 \\
\hline Equal variances not assumed & & & 3.004 & 67.85 & .004 & 1.04286 \\
\hline
\end{tabular}

\section{DISCUSSION}

The present study showed that the performance of the weekly quiz group was significantly better than that of the control group. Along the same line, Geist and Soehren (1997) and Ballard and Johnson (2004) found evidence in favor of weekly quizzes compared with no quiz indicating that weekly quizzes enhance students' performance. The finding of the present study is also consistent with studies such as Martin and Srikameswaran (1974), Graham (1999) and Kamuche (2005), who confirmed that students who received weekly quizzes outscored students who received no quiz during the course.

Surprisingly enough, in contrast with the aforementioned findings, Haberyan (2003), in his study, found that there was no significant difference between the weekly quiz group and no-quiz control group students' performance in the class.

There are several reasons why more frequent testing when compared with infrequent testing has a more influential impact on students' learning. One of the reasons behind the success of weekly quizzes may be attributed to class attendance; weekly quizzes make students come to class consistently. As previous studies have shown, there is a positive relationship between frequent testing and students' attendance in the classroom (Wilder et al., 2001; Zarei, 2008) which consequently results in a positive effect on overall course grades (Wilder et al., 2001; Clump et al., 2003) since it provides more opportunities for learning in the classroom.

As frequent testing motivates students to do extra work in the class (Martin \& Srikameswaran, 1974), it makes the long-term retention of the materials possible. The short nature of frequent quizzes facilitates and reinforces the learning of materials in a systematic way, because everything is being tested and then stored in small chunks systematically (Fulkerson \& Martin, 1981) Furthermore, frequent testing makes students come to class with preparation (Dustin, 1971; Standlee \& Popham, 1960). Through frequent testing, small amounts of materials are tested. Therefore, these materials are processed more deeply and meticulously and lend themselves to more efficient learning (Standlee \& Popham, 1960). Furthermore, frequent testing produces a lot of small discussions between the teacher and students, which again helps learners retain the material for a longer period of time (Selakovich, 1962; Farhady, Jafarpur, \& Birjandi, 1994). Fitch, Drucker, and Norton (1951) also found that students who were tested on a weekly basis were engaged in more discussions and interaction in the class.

As frequent quizzes expose students to the materials covered in the class more regularly, there is the probability that students become more familiar with the instructional expectations of the teacher and the methodology. In other words, they become more testwise and detect the kinds of questions to be included in the final exam (Farhady et al., 1994). 
Still another reason for the better performance of the weekly quiz group might be that quizzes create a lot of extrinsic motivation for the students since students want to obtain good grades in the course; therefore, they try hard and spend a lot of time preparing for the quizzes (Dustin, 1971; Standlee \& Popham, 1960). Although, motivation and interest are the incentives for learning, Zarei (2008) argues that "motivation is not always the cause of good grades; it may well be the result of them. Quizzes increase course grades by supplying motivation, and motivate students to study by improving their grades" (pp. 5-6). In addition, when students take tests regularly, they become accustomed to the tests, and this reduces their sense of test anxiety. Therefore, when taking the final examination, they experience lower levels of debilitative test anxiety compared with those who take tests less frequently. The lower levels of debilitative test anxiety may, in turn, boost the learners' test performance.

The findings of the present study may have implications for teachers, learners, and curriculum designers. The findings suggest that frequent testing should be treated more fairly in the field and be looked upon as a valuable source for all stakeholders in English language education including policy makers, teachers, students, and parents. Another theoretical promise of this study is that both this study and the current literature on frequent testing suggest that students highly welcome frequent quizzes because of different reasons they harbor; therefore, it is time to call for a renewal of the role of frequent testing in the field.

\section{REFERENCES}

[1] Ballard, C. L. \& Johnson, M. F. (2004). Basic Math Skills and Performance in an Introductory Economics Class. Journal of Economic Education, 35(1), 3-24.

[2] Basol, G. \& Johnson, G. (2009). Effectiveness of frequent testing over achievement: A meta-analysis study. International Journal of Human Sciences, 6(2), 99-120.

[3] Bangert-Drowns, R. L., Kulik, J. A., \& Kulik, C. C. (1991). Effects of frequent classroomtesting. Journal of Educational Research, 85(2), 89-99.

[4] Brown, H. D. (2004). Language assessment: Principles and classroom Practices. US. Longman.

[5] Clump, M. A., Bauer, H., \& Alex, W. (2003). To attend or not to attend: Is that a good question? The Internet TESOL Journal, 8(12), Retrieved March 12, 2010, from http://findarticles.com/p/articles/mi

[6] Connor-Greene, P. A. (2000). Assessing and Promoting Student Learning Between Teaching and Testing. Teaching of Psychology, 27(2), 84-88.

[7] Dineen, P., Taylor, J., \& Stephens, L. (1989). The effect of testing frequency upon the achievement of high school mathematics course. School Science and Mathematics, 89(3), 197-200.

[8] Dustin, D. S. (1971). Some effects of exam frequency. The Psychological Record, 21(3), 409-414.

[9] Ellis, R. (2005). Instructed language learning and task-based teaching. In E. Hinkel (Ed.), Handbook of research in second language teaching and learning (713-728). Mahwah, New Jersey: Lawrence Erlbaum Associates.

[10] Farhady, H., Jafarpur, A., \& Birjandi, P. (1994). Testing language skills: From theory to practice. Tehran: SAMT Publication.

[11] Fitch, M. L., Drucker, A. J., \& Norton, J. R. (1951) Frequent testing as a motivating factor in large lecture classes. The Journal of Educational Psychology, 42(1), 1-20.

[12] Fulkerson, F. F. \& Martin, G. (1981). Effects of exam frequency on student performance, evaluations of instructor, and test anxiety. Teaching of Psychology, 8(2), 90-93.

[13] Geist, J. R. \& Soehren, S. E. (1997). The Effect of Frequent Quizzes on Short- and Long-Term Academic Performance. Journal of Dental Education, 61(4), 339-345.

[14] Haberyan, K. A. (2003). Do Weekly Quizzes Improve Student Performance on General Biology Exams? American Biology Teacher, 65(2), 110-114.

[15] Hughes, A. 1989. Testing for Language Teachers. Cambridge: Cambridge University Press.

[16] Johnson, B. C. Kiviniemi, M. T. (2009). The effect of online chapter Quizzes on Exam performance in an undergraduate Social psychology course. Teach Psychology, 36(1), 33-37.

[17] Jones, C. H. (1984). Interaction of absences and grades in a college course. Journal of Psychology, $116,133-136$.

[18] Kamuche, F. U. (2005). Do weekly quizzes improve student performance? Academic Exchange Quarterly, 9(3), 188-193.

[19] Kamuche, F. U. (2007). The effect of unannounced quizzes on students' performance: Further Evidence. College Teaching Methods \& Styles Journal, 3(2), 21-25.

[20] Keys, N. (1934). The influence on learning and retention of weekly as opposed to monthly tests. Journal of Educational Psychology, 25, 427-436.

[21] Khalaf, A. S. S. \& Hanna, G. S. (1992). The impact of classroom testing frequency on high school students' achievement. Contemporary Educational Psychology, 17(1), 71-77.

[22] Kling, N., Miller, C., \& Reardon, J. (2005). The impact of testing frequency on student performance 
in a marketing course. Journal of Education for Business, 81(2), 67-72.

[23] Long, M. (1985). A role for instruction is second language acquisition: Task-based language teaching. In K. Hyltenstam \& M. Pienemann (Eds.), Modelling and assessing second language acquisition (pp. 377-393). Clevedon, UK: Multilingual Matters.

[24] Marcell, M. (2008). Effectiveness of regular online quizzing in increasing class participation and prepration. International Journal for the Scholarship of Teaching and Learning, 2(1), 1-9.

[25] Marshall, B. (2007). A crisis for efficacy? Education Review, 20(1), 29-35.

[26] Martin, R. R. \& Srikameswaran, K. (1974). Correlation between frequent testing and student performance. Journal of Chemical Education, $51(7), 485-486$.

[27] Pica, T. (1983). Adult acquisition of English as a second language under different conditions of exposure. Language Learning, 33, 465-497.

[28] Prabhu, N. S. (1987). Second language pedagogy. Oxford, UK: Oxford University Press.

[29] Roediger, H. L. \& Karpicke, J. D. (2006). Testenhanced learning: Taking memory tests improves long-term retention. Psychological Science, 17(3), 249-255.

[30] Selakovich, D. (1962). An experiment attempting to determine the effectiveness of frequent testing as an aid to learning in beginning college courses in American government. The Journal of Educational Research, 55(4), 178-180.

[31] Standlee, L. S. \& Popham, W. J. (1960). Quizzes' contribution to learning. Journal of Educational Psychology, 51(6), 322-325.

[32] Turney, A. H. (1931). The effect of frequent short objective tests upon the achievement of college students in educational psychology. School and Society, 33, 760-762.

[33] Weinstein, S. E. \& Wu, S. W. (2009). Readiness Assessment Tests versus Frequent Quizzes: Student Preferences. International Journal of Teaching and Learning in Higher Education. 21(2), 181-186.

[34] White, R. (1988). The ELT curriculum. Oxford, UK: Blackwell.

[35] Widdowson, H. (1998). Skills, abilities, and contexts of reality. Annual Review of Applied Linguistics, 18, 323-333.

[36] Wilder, D. A., Flood, W. A., \& Stromsnes, W. (2001). The use of random extra credit quizzes to increase student attendance. Journal of
Instructional Psychology. Retrieved March 7, 2010, From http://findarticles.com/p/articles/mi

[37] Zarei, A. A. (2008). On the Learnability of three categories of Idioms by Iranian EFL learners. Journal of Humanities of the University of Kerman, 2(2), 82-100.

Valeh Gholami is currently a $\mathrm{PhD}$ candidate of TEFL studying at University of Tabriz, Iran.

Mostafa Morady Moghaddam is currently a $\mathrm{PhD}$ candidate of TEFL at the department of English language and literature, University of Tabriz, Iran. 